
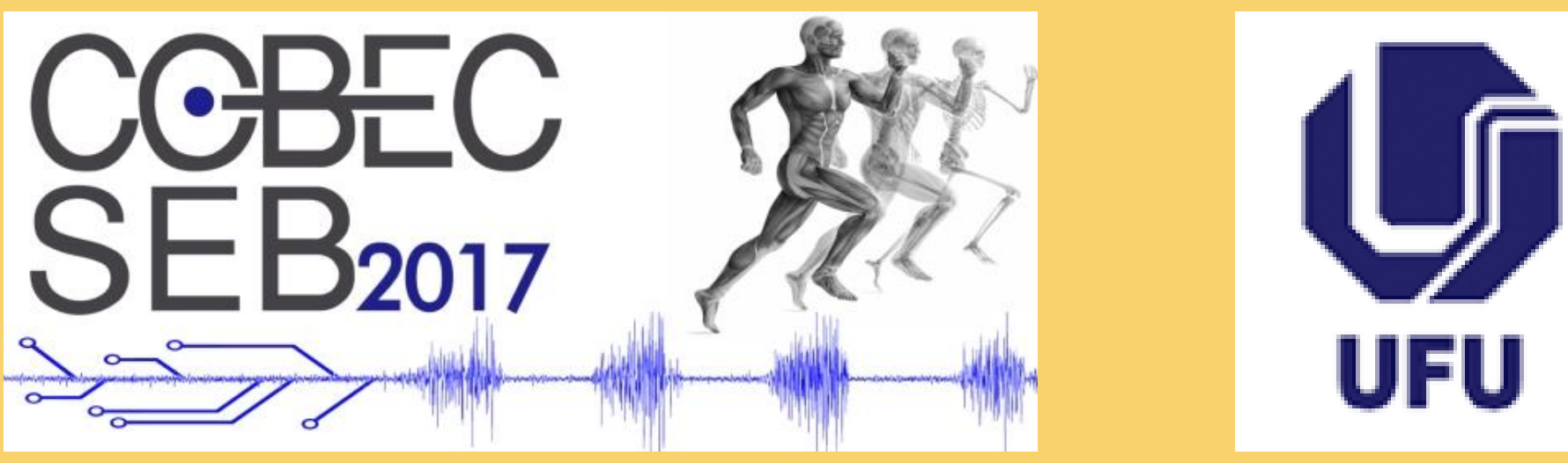

\title{
ANÁLISE DE APRENDIZAGEM NA REALIZAÇÃO DE TAREFAS DE CONTROLE EM UMA INTERFACE HOMEM-COMPUTADOR COM PROTOCOLOS EXPERIMENTAIS COM DIFICULDADES CRESCENTES
}

L. M. D. Luiz*, S. C. Costa*, G. M. Silva*, A. Pericles**,

C. M. O. Queiroz* e A. O. Andrade*

e-mail: luizamaire@gmail.com 


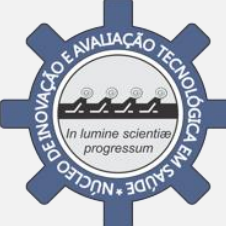
NIATS

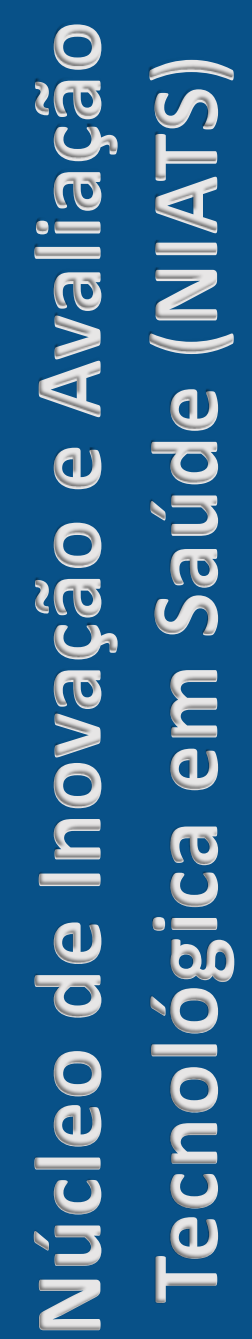

Motivação
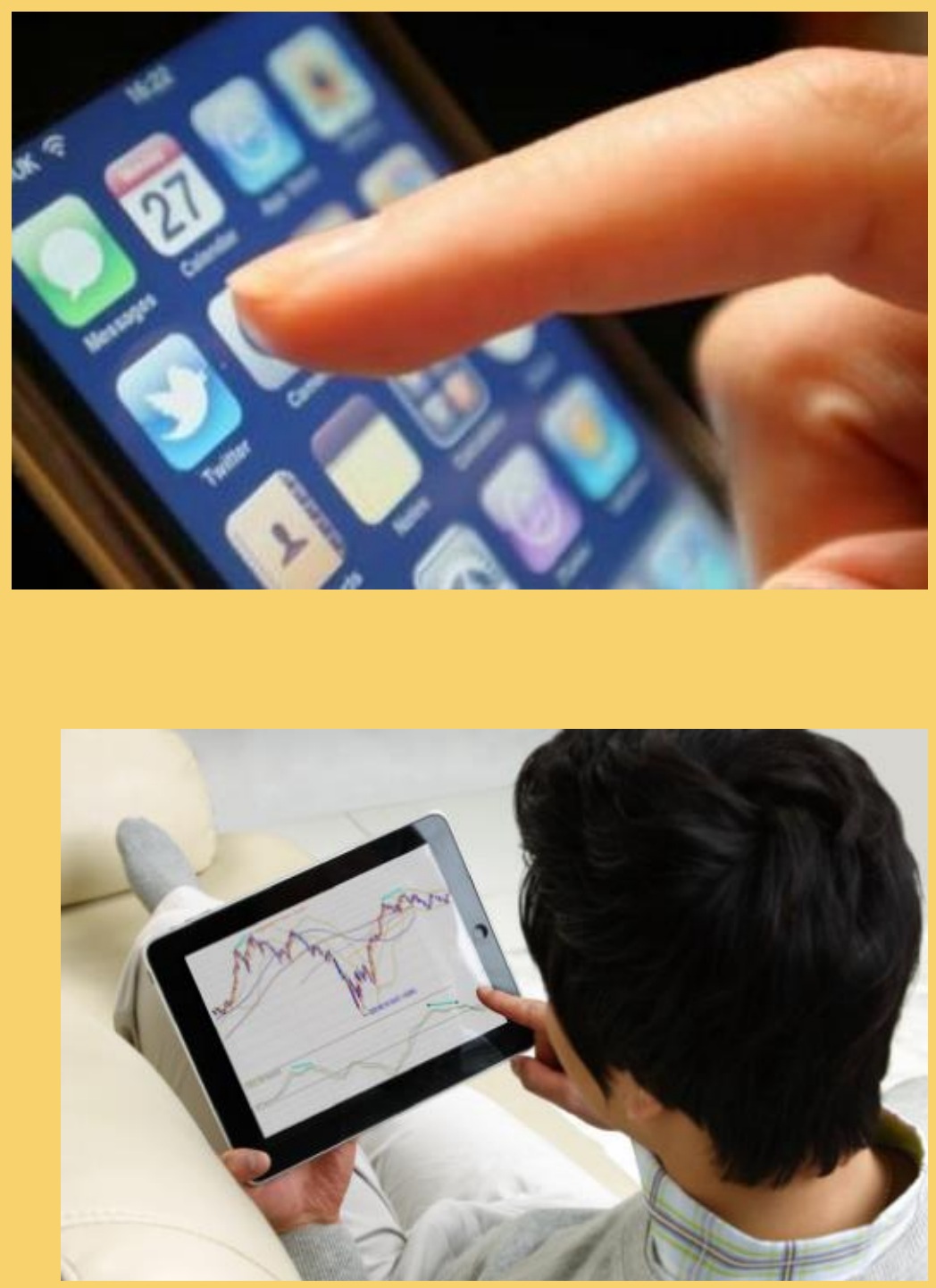

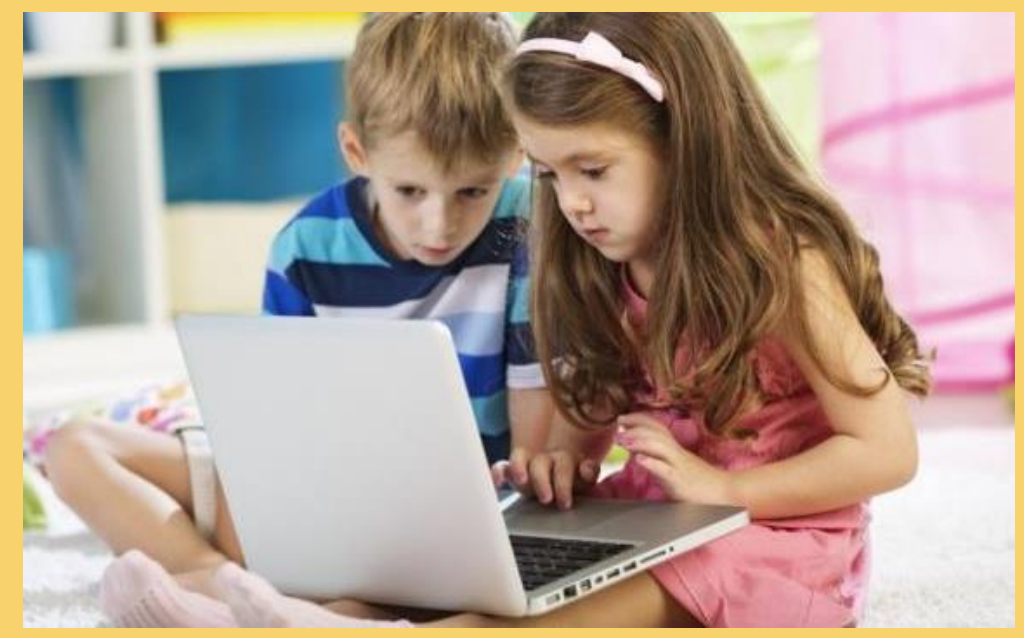




\section{Introdução}

-Habilidades motoras comprometidas;

-Movimentos voluntários remanescentes;

- Potencializar as capacidades residuais das pessoas com deficiência, criando possibilidades e condições para desempenho funcional de cada usuário. 


\section{Introdução}

- Desenvolvimento de ferramentas adaptativas e tecnológicas para possibilitar a interação com computadores e navegação na internet;
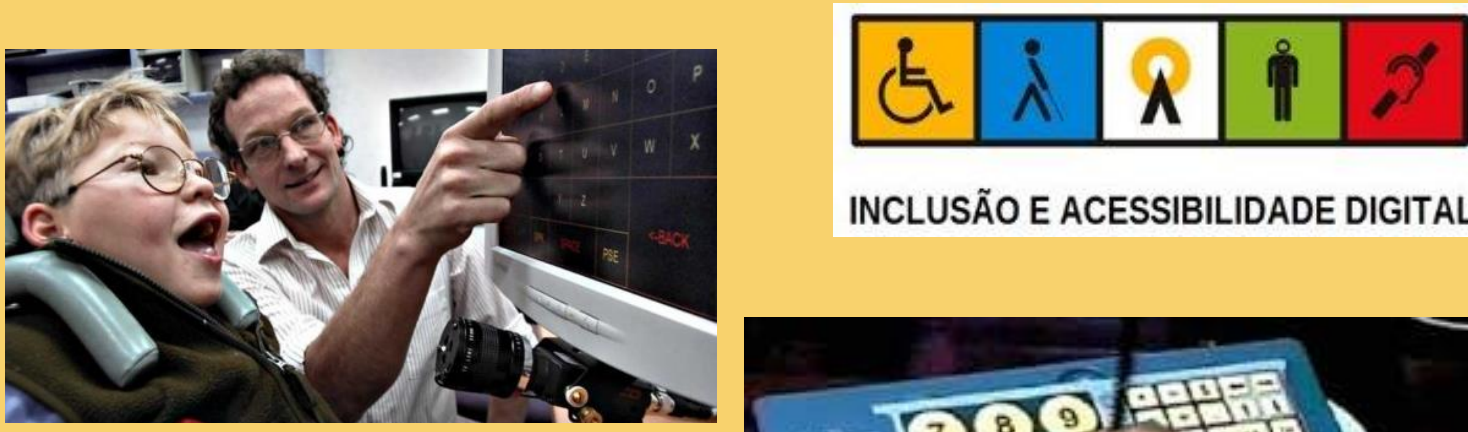

INCLUSÃO E ACESSIBILIDADE DIGITAL
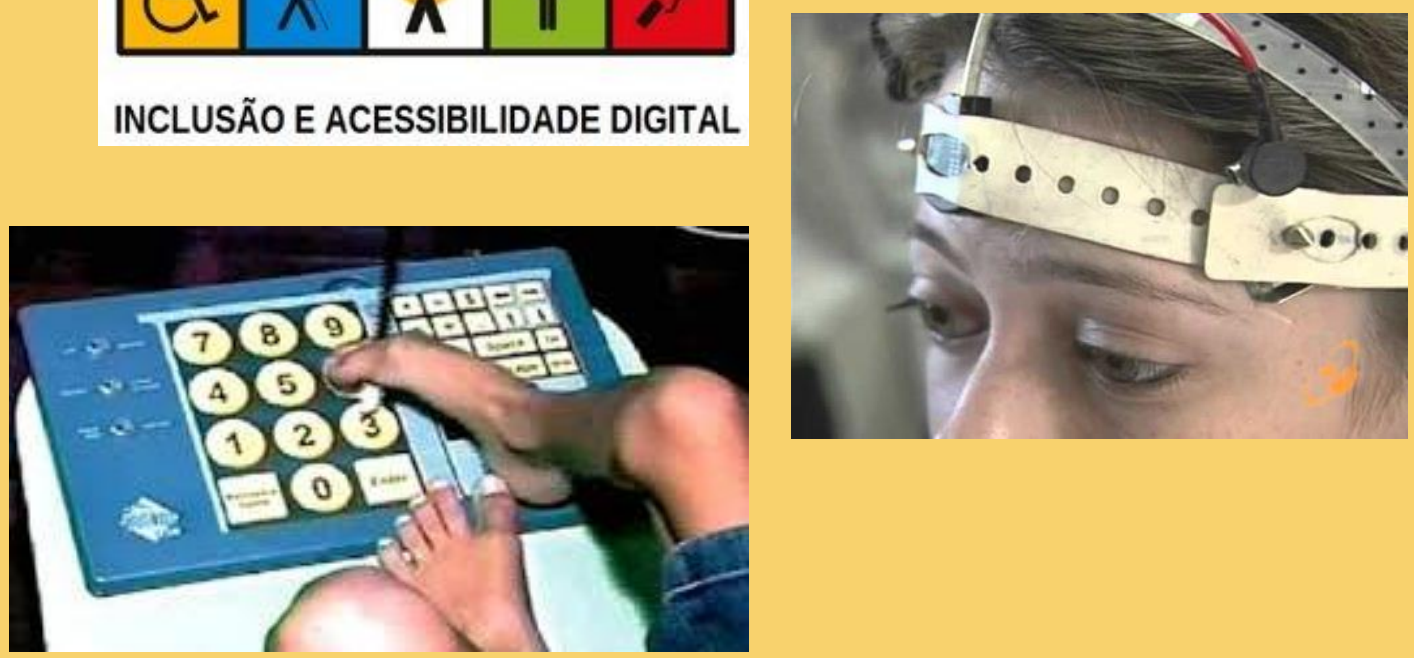


\section{Introdução}

- As limitações e aptidões de cada usuário, no período de aprendizagem e manipulação do equipamento, é de extrema importância a implementação de interfaces gráficas de aprendizagem eficientes;

- As interfaces são desenvolvidas para maximizar o foco do usuário, na tarefa proposta e devem propiciar níveis crescentes de dificuldade durante a execução. 


\section{Objetivo}

- O objetivo desse trabalho é analisar a aprendizagem dos indivíduos que realizarão tarefas de controle de uma interface Homem-Computador ao longo do protocolo experimental. 


\section{Projeto}

- Os protocolos de avaliação da interface HomemComputador desta pesquisa consistem na captação simultânea dos sinais de eletromiografia e encefalografia durante a realização de tarefas, empregando uma interface de aprendizagem.

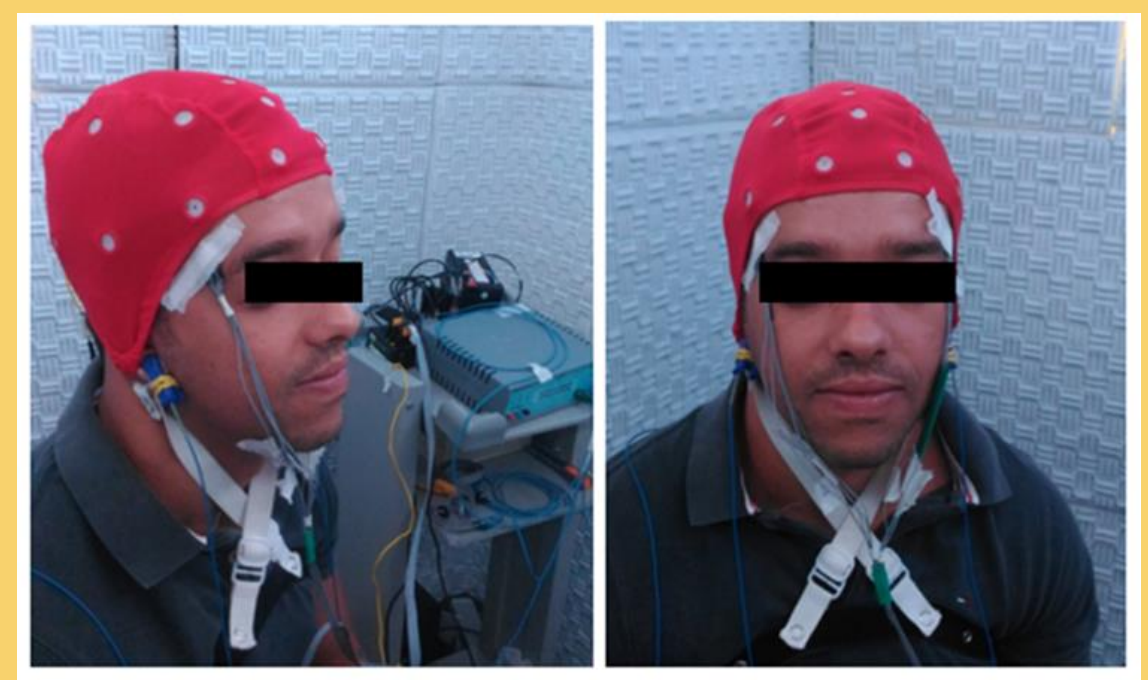




\section{Materiais e Métodos}

Esse trabalho, analisa especificamente, a variação do tempo da execução da tarefa proposta ao longo dos dias de execução do protocolo experimental.

\section{Sujeitos}

- Cinco voluntários sem comprometimentos motores e cognitivos. 


\section{Materiais e Métodos}

\section{Interface Gráfica de Aprendizagem (IGA)}

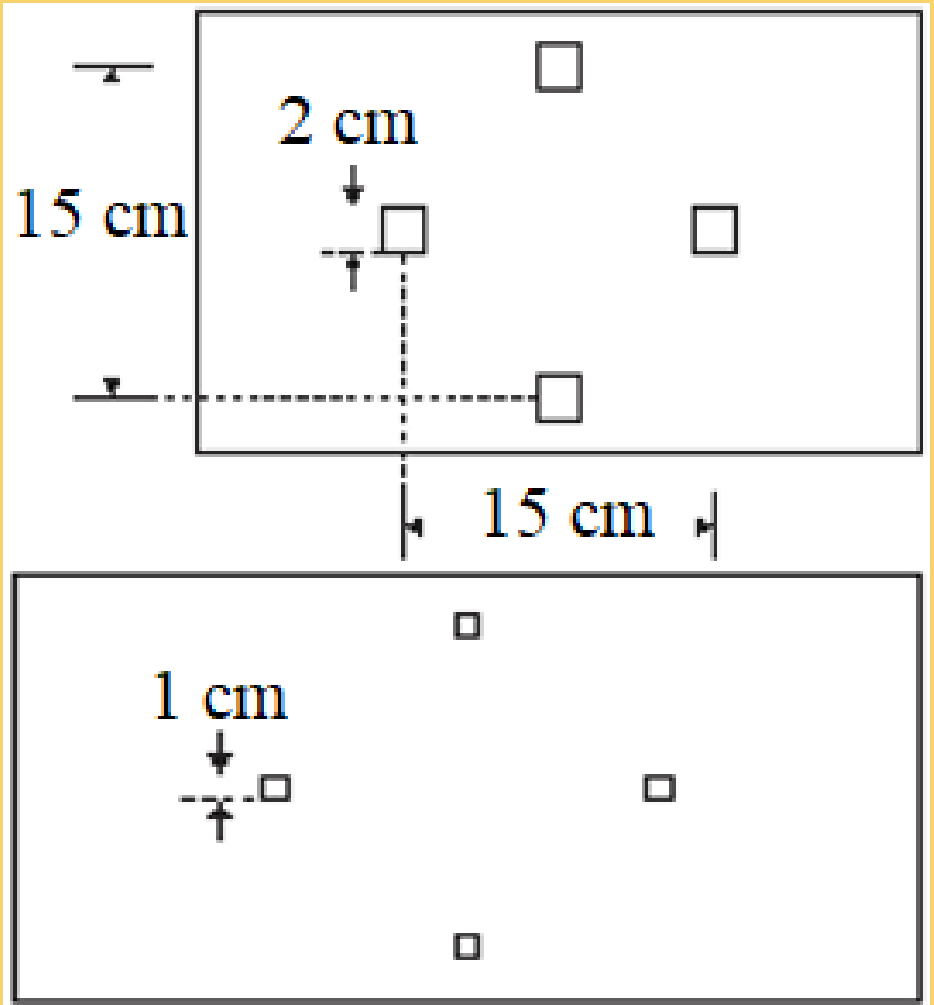

Protocolo 1, 2 e 3.

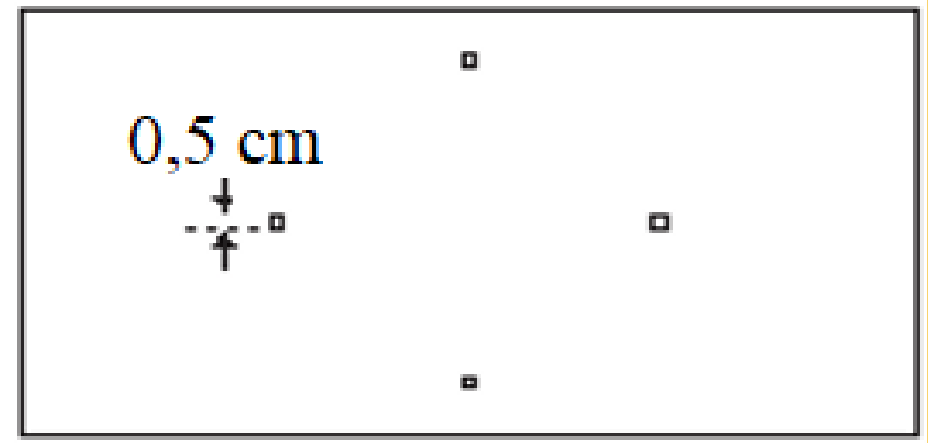




\section{Materiais e Métodos}

\section{Protocolo experimental}

O protocolo é realizado em cinco dias consecutivos com a execução da tarefa uma vez por dia.

A IGA, apresenta alvos aleatoriamente, o controle do mouse é feito por meio do comando dos sinais mioelétricos. 


\section{Materiais e Métodos}

Análise dos dados

Análise do tempo gasto para execução da tarefa, mais especificamente o intervalo de tempo entre os cliques, e mostrado de forma descritiva.

Foram divididas de duas formas, uma análise intervoluntário e uma análise intragrupo. 


\section{Resultados}

\section{NIATS}

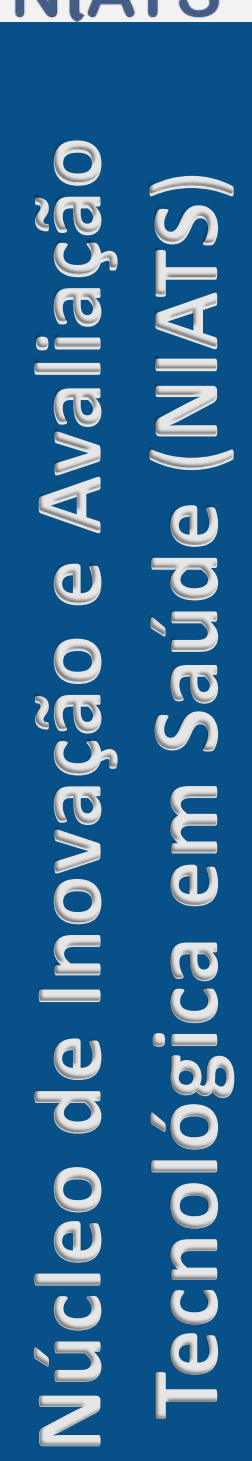
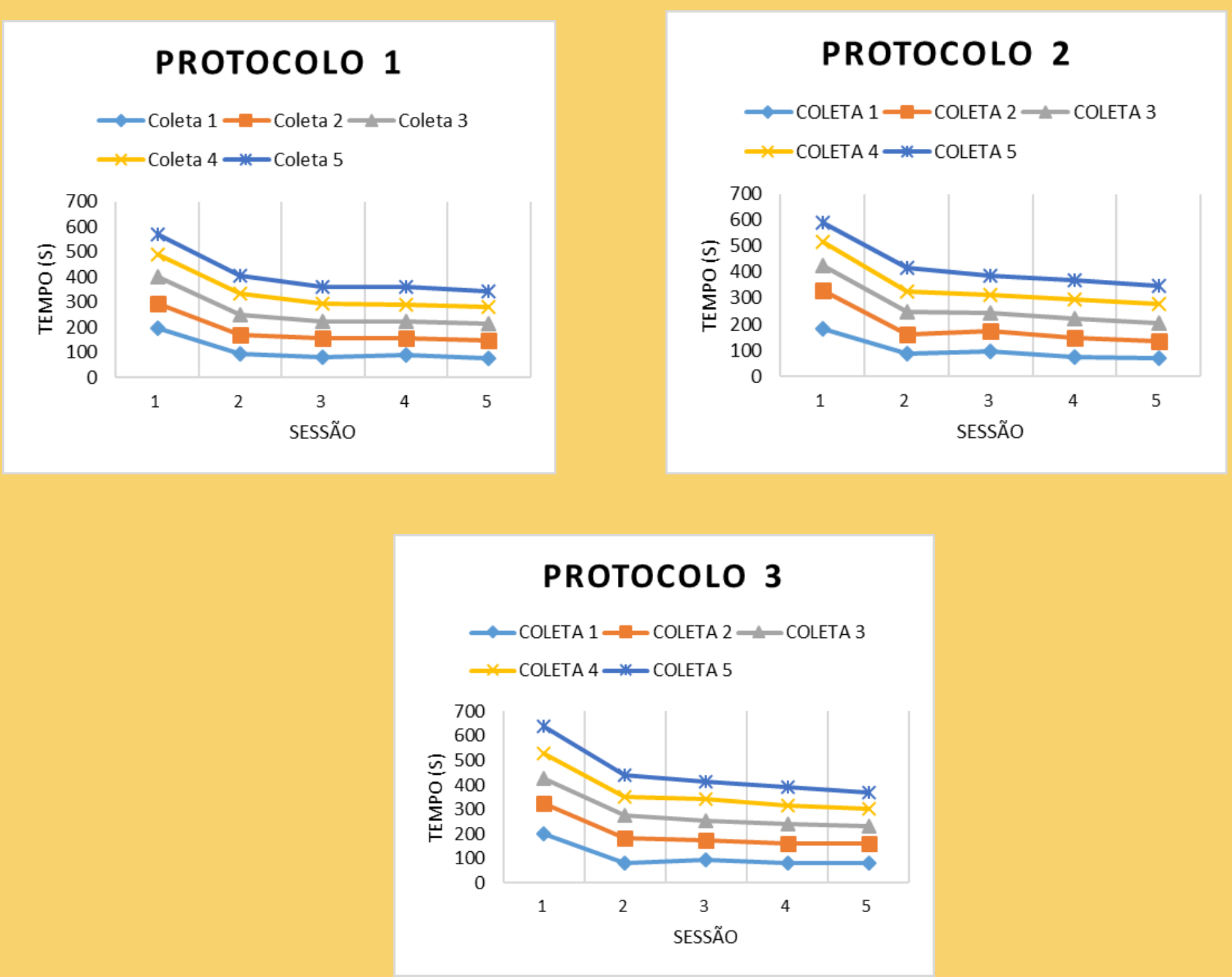


\section{Resultados}

\section{TEMPO TOTAL POR PROTOCOLO}

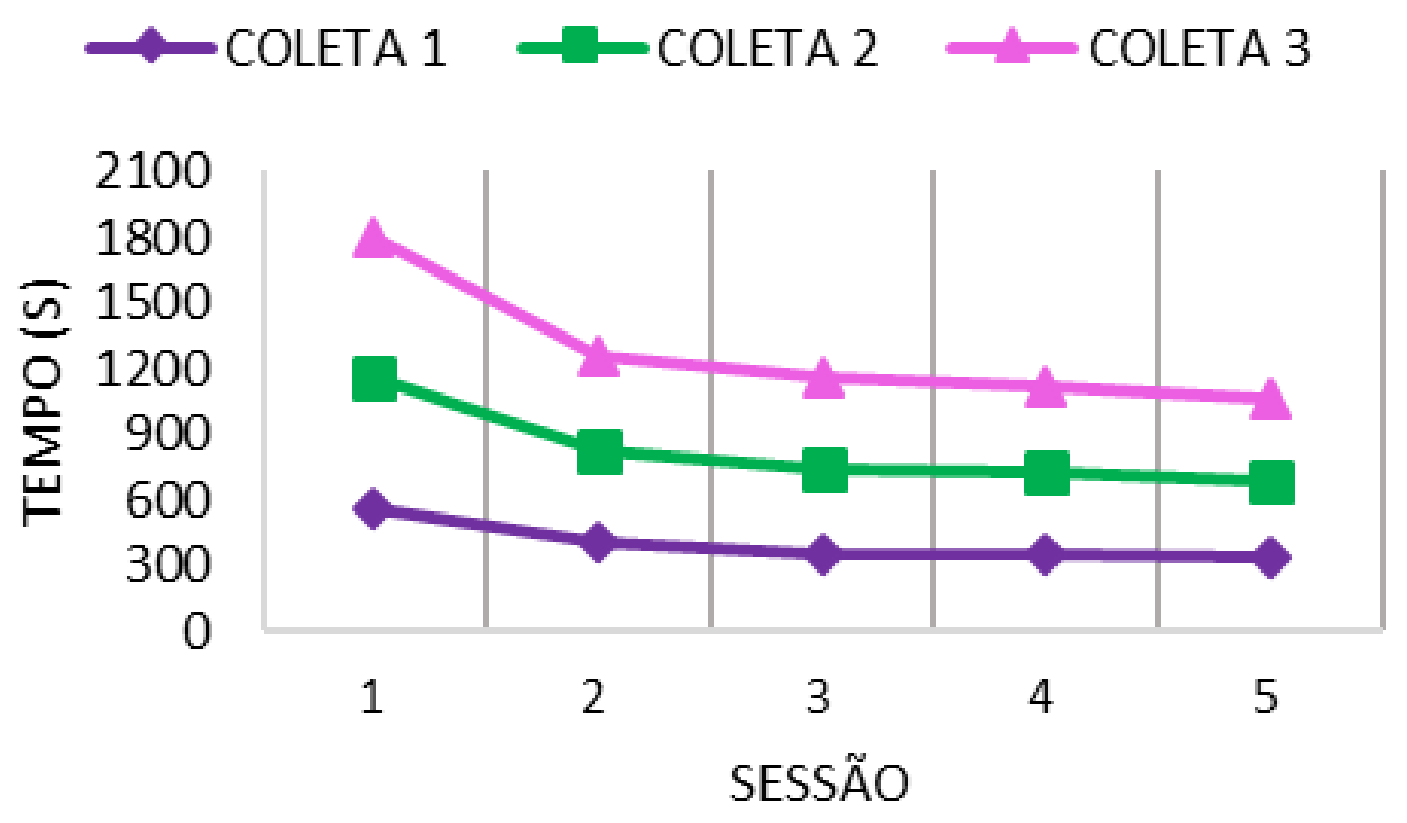




\section{Discussão e Conclusão}

- A IGA proposta após testada apresenta boa aplicabilidade;

- Além de ter um crescimento na dificuldade como proposto por Fitts [6];

-Validação da ferramenta;

- Uso constante apresenta uma evolução na performance do usuário. 

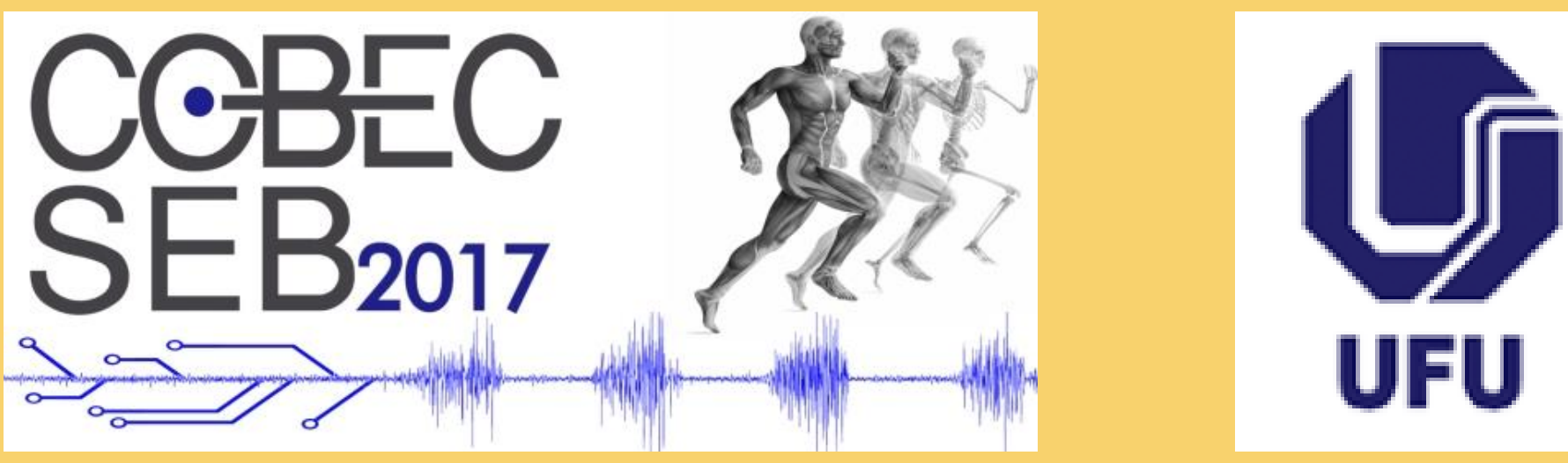

\section{ANÁLISE DE APRENDIZAGEM NA REALIZAÇÃO DE TAREFAS DE CONTROLE EM UMA INTERFACE HOMEM-COMPUTADOR COM PROTOCOLOS EXPERIMENTAIS COM DIFICULDADES CRESCENTES}

L. M. D. Luiz*, S. C. Costa*, G. M. Silva*, A. Pericles**,

C. M. O. Queiroz* e A. O. Andrade*

e-mail: luizamaire@gmail.com 